Vol. 1 , No. 1 , Januari 2019

\title{
FAKTO- FAKTOR YANG BERHUBUNGAN DENGAN PENGGUNAAN METODE KONTRASEPSI JANGKA PANJANG WANITA USIA SUBUR
}

\author{
Factors Related to the Use of Long-Term Contraception Method in Fertilizer Age Women
}

\author{
Yuli Suryanti \\ Jurusan Kebidanan, Poltekkes Kemenkes, Jambi \\ e-mail: yulisuryanti107@yahoo.com
}

\begin{abstract}
Abstrak
Banyak faktor yang mempengaruhi Penggunaan metode kontrasepsi jangka panjang antara lain pengetahuan, umur dan partisipasi suami. Berdasarkan data Dinas Kesehatan Kota Jambi didapatkan bahwa Puskesmas Paal V dengan jumlah PUS 7.220 orang, dengan KB aktif berjumlah 5.802 orang. Metode kontrasepsi jangka Panjang (MKJP) yang digunakan adalah Implant 3,01\%, AKDR 9,5\%, MOW 3,1\%, dan MOP $0,3 \%$. Sedangkang Non MKJP adalah suntik $60,1 \%$, Pil 21,6\% dan kondom 2,46\%. Penelitian ini merupakan penelitian analitik dengan menggunakan rancangan cross sectional. Populasi adalah seluruh wanita usia subur di Puskesmas Paal V Kota Jambi Tahun 2018 yang berjumlah 5.802 orang. Penelitian ini menggunakan teknik Accidental sampling. Pengumpulan data primer dengan kuesioner. Penelitian dilakukan dari bulan Mei s/d Agustus 2018 dengan analisis Univariat dan Bivariat dengan uji chi squre. Hasil penelitian menunjukkan bahwa dari 95 responden yang diteliti tentang penggunaan metode kontrasepsi jangka panjang responden yang menggunakan MKJP sebanyak 52 responden. Hasil penelitian ini dapat dilihat bahwa responden yang memiliki pengetahuan kurang baik sebanyak 71 responden. Mayoritas umur sebanyak 50 responden yakni umur 25-35 tahun . mayoritas partisipasi suami yang mendukung sebanyak 52 responden. Ada hubungan pengetahuan dengan penggunaan MKJP dengan p-value $(0,000)<0,05$. Ada hubungan umur dengan penggunaan MKJP dengan p-value $(0,000)<0,05$. Ada hubungan partisipasi suami dengan penggunaan MKJP dengan p-value $(0,000)<0,05$.
\end{abstract}

Kata Kunci : Pengetahuan; Partisipasi suami; MKJP; Umur

\begin{abstract}
Many factors affect the long-term use of contraceptive methods such as knowledge, age and husband's participation. Based on data from the Jambi City Health Office, it was found that Paal V Health Center with a total number of PUS was 7,220 people, with active family planning totaling 5,802 people. Long-term contraceptive methods (MKJP) used were Implant 3.01\%, IUD 9.5\%, MOW 3.1\%, and MOP 0.3\%. Non MKJP sedang is $60.1 \%$ injections, $21.6 \%$ pills and $2.46 \%$ condoms. This research is an analytic research using cross sectional design. The population is all women of childbearing age at Paal V Health Center in Jambi City in 2018, totaling 5,802 people. This study uses Accidental sampling technique. Primary data collection by questionnaire. The study was conducted from May to August 2018 with Univariate and Bivariate analysis with chi square test. The results showed that out of 95 respondents examined about the use of long-term contraceptive methods, respondents who used MKJP were 52 respondents. The results of this study can be seen that respondents who have poor knowledge are 71 respondents. The majority of the age of 50 respondents is aged 25-35 years. the majority of husband's participation supported 52 respondents. There is a relationship of knowledge with the use of MKJP with a p-value $(0,000)<0.05$. There is a relationship between age and MKJP usage with a p-value $(0,000)<0.05$. There is a relationship between husband's participation and the use of MKJP with a p-value $(0,000)<0.05$.
\end{abstract}

Keywoards : Age; Husband's Participation; Knowledge; MKJP. 


\section{PENDAHULUAN}

Menurut World Health Organization (WHO) Expert Committe 1997 : “ keluarga berencana adalah tindakan yang membantu pasangan suami istri untuk menghindari kehamilan yang tidak diinginkan, mendapatkan kelahiran yang memang sangat diinginkan, mengatur interval diantara kehamilan, mengontrol waktu saat kelahiran dalam hubungan dengan usia suami-istri serta menentukan jumlah anak dalam keluarga". Secara umum keluarga berencana dapat diartikan sebagai suatu usaha yang mengatur banyaknya kehamilan sedemikian rupa sehingga berdampak positif bagi ibu, bayi, ayah serta keluarganya yang bersangkutan tidak akan menimbulkan kerugian sebagai akibat langsung dari kehamilan tersebut. Diharapkan dengan adanya perencanaan keluarga yang matang kehamilan merupakan suatu hal yang memang sangat diharapkan sehingga akan terhindar dari perbuatan untuk mengakhiri kehamilan dengan aborsi ${ }^{1}$.

Metode kontrasepsi jangka panjang (MKJP) merupakan metode kontrasepsi yang sangat efektif untuk menurunkan angka kelahiran. Metode kontrasepsi jangka panjang adalah kontrasepsi yang dapat dipakai dalam jangka waktu lama, lebih dari 2 tahun, efektif dan efisien untuk tujuan menjarangkan kelahiran lebih dari 3 tahun atau mengakhiri kehamilan pada pasangan yang sudah tidak ingin tambah anak lagi. Jenis metode yang termasuk kedalam MKJP adalah kontrasepsi mantap pria dan wanita (tubektomi dan vasektomi), implant dan IUD ${ }^{2}$.

Dari data WHO (1990) didapatkan bahwa diseluruh dunia terjadi lebih dari 100 x 10(6) sanggama setiap harinya dan terjadi 1 juta kelahiran baru per hari dimana 50\% diantaranya tidak direncanakan dan 25\% tidak diharapkan. Dari 150.000 kasus abortus provokatus yang terjadi perhari, 50.000 diantaranya abortus ilegal dan lebih dari 500 perempuan meninggal akibat komplikasi abortus tiap harinya ${ }^{3}$. Berdasarkan hasil estimasi tahun 2016 jumlah penduduk Indonesia sebesar 258.704 .986 jiwa dengan tingkat laju pertubuhan penduduk di Indonesia yang masih tinggi yakni sekitar 1,49\% atau sekitar 4 juta penduduk pertahun, hasil ini akan meningkat pada tahun 2018 sebesar 265.015.313 jiwa (Pusdatin Kemenkes RI, 2016). Sesuai target pemerintah idealnya laju pertumbuhan penduduk 12 juta pertahun sesuai target di $2025^{2}$.

Tren penggunaan MKJP menunjukkan situasi yang wajar, dimana persentase pengguna MKJP meningkat sejalan dengan meningkatnya usia PUS. Namun demikian, peningkatan persentase pengguna MKJP tidaklah signifikan. Kenyataannya, bahwa persentase penggunaan kontrasepsi suntikan dan pil di kelompok usia tua relatif masih besar (>60\%) untuk kelompok usia 45-49 tahun dan lebih tinggi lagi untuk kelompok usia yang lebih muda. Bila dikaitkan dengan tujuan penggunaan kontrasepsi serta efektivitasnya, tren yang ada tidak memberikan gambaran yang positif karena sebagian besar peserta KB masih menggunakan kontasepsi jangka pendek berdasarkan data Susenas 2015.

Berdasarkan penelitian yang dilakukan oleh Putri Hariyani dan Hari Basuki bahwa umur, jumlah anak dan pengetahuan merupakan faktor yang mempengaruhi rendahnya keikutsertaan penggunaan kontrasepsi jangka panjang di Polindes Tebalo Kecamatan Manyar Gresik ${ }^{4}$. Hasil penelitian oleh Rino Siswanto dan Achmad Farich bahwa ada hubungan antara dukungan suami dan efek samping dengan pemilihan MKJP ${ }^{5}$. Hasil penelitian oleh Nislawaty bahwa sebagian responden memiliki pengetahuan yang rendah tentang MKJP, terdapat hubungan status ekonomi dengan pemakaian MKJP, serta terdapat hubungan pendidikan dengan pemakaian MKJP ${ }^{6}$

Jumlah peserta $\mathrm{KB}$ secara nasional berdasarkan alat kontrasepsi terbanyak dipakai diantaranya adalah suntik $29,0 \%$, Pil 12,1\%, Impant 4,7\%, dalam rahim 4,7\%, MOW 3,8\%, Kondom 2,5\%, dan MOP 0,2\% . Jumlah PUS di Provinsi Jambi 619.581 orang, metode kontrasepsi yang paling banyak dipakai adalah suntik 34,8\%, Pil 14,5\%, implant 5,5\%, AKDR 3,8\%, Kondom 2,5\%, MOW 2,2\%, dan MOP $0,2 \%^{7}$. 
Vol. 1, No. 1, Januari 2019

Di Provinsi Jambi sendiri pada tahun 2016 jumlah penduduk sebesar 3.458.926 jiwa juga mengalami kenaikan pada tahun 2018 jumlah penduduk Provinsi Jambi berjumlah 3.570.272 jiwa. Cakupan peserta KB baru dan KB aktif menurut jenis kontrasepsi yang dipakai, KB baru diantaranya suntik $51,53 \%$, pil $23,17 \%$, implant $11,37 \%$, alat kontrasepsi dalam rahim $7,23 \%$, kondom $4,78 \%$, MOW 1,73\%, MOP 0,18\%. Sedangkan pengguna KB aktif diantaranya suntik 47,96\%, pil 22,81\%, implant $11,20 \%$, AKDR 10,61\%, kondom 3,23\%, MOW 3,54\%, MOP 0,64\% ${ }^{8}$.

Peserta KB baru dan KB aktif menunjuk pola yang sama dalam pemilihan jenis alat kontrasepsi sebagian peserta $\mathrm{KB}$ baru maupun peserta $\mathrm{KB}$ memilih suntikan dan pil sebagai alat kontrasepsi. Namun demikian perlu diperhatikan tingkat efektifitas suntikan dan pil dalam pengendalian kehamilan dibandingkan jenis kontrasepsi lainnya ${ }^{8}$.

Data dari Dinas Kesehatan Kota Jambi didapatkan bahwa jumlah PUS di Kota Jambi 124.067 orang, dengan KB aktif berjumlah 95.535 orang. Metode kontrasepsi jangka Panjang (MKJP) yang digunakan adalah AKDR 1,31\%, Impant 2,12\%, MOW 0,5\% dan MOP 0,01\%. Sedangkang Non MKJP adalah suntik 39,5\%, Pil 15,2\% dan kondom 2,2\%. Data dari Dinas Kesehatan Kota Jambi didapatkan bahwa Puskesmas Paal V dengan jumlah PUS 7.220 orang, dengan KB aktif berjumlah 5.802 orang.Metode kontrasepsi jangka Panjang (MKJP) yang digunakan adalah Implant 3,01\%, AKDR 9,5\%, MOW 3,1\%, dan MOP 0,3\%. Sedangkang Non MKJP adalah suntik 60,1\%, Pil 21,6\% dan kondom $2,46 \%$.

Dari data Puskesmas Paal V triwulan 1 didapatkan data wilayah Kelurahan Paal V memiliki jumlah KB aktif 1.964. metode kontrasepsi jangka panjang (MKJP) yang digunakan adalah IUD 10,2\%, implant 3,9\%, MOW 2,9\%, MOP 0. Sedangkan data wilayah Kelurahan Suka Karya memiliki jumlah KB aktif 1.082. metode kontrasepsi jangka panjang (MKJP) yang digunakan adalah IUD 6,6\%, implant 3.8\%, MOW 3,7\%, MOP 0.Sedangkan data wilayah Kelurahan Simpang III Sipin memiliki jumlah KB aktif 2.756. metode kontrasepsi jangka panjang (MKJP) yang digunakan adalah IUD $10,1 \%$, implant $2,1 \%$, MOW 2,9\%, MOP $0^{9}$.

Berdasarkan uraian diatas, perlu dilakukan penelitian tentang " faktor - faktor yang berhubungan dengan penggunaan metode kontrasepsi jangka panjang (MKJP) pada wanita usia subur di Puskesmas Paal V Kota Jambi tahun 2018".

\section{METODE PENELITIAN}

Penelitian ini adalah penelitian yang bersifat analitik, dengan rancangan cross sectional yaitu penelitian yang dilakukan pada satu waktu dan satu kali, untuk mencari hubungan antara variabel independen faktor resiko) dengan variabel dependen (efek) yaitu faktor yang mempengaruhi penggunaan metode kontrasepsi jangka panjang (MKJP) di Puskesmas Paal V Kota Jambi tahun 2018. Penelitian ini dilaksanakan di Puskesmas Paal V Kota Jambi. Waktu penelitian dilakukan pada bulan Mei- Agustus 2018. Populasi dalam penelitian ini adalah seluruh wanita usia subur yang menjadi akseptor KB yang berada di Puskesmas Paal V Kota Jambi tahun 2018 sebanyak 5.802 orang. Sampel dalam penelitian ini adalah wanita usia subur yang berada di Puskesmas Paal V Kota Jambi dengan jumlah 95 akseptor pengampilan sampel dalam penelitian ini dengan menggunakan teknik accidental sampling.

\section{HASIL DAN PEMBAHASAN}

\subsection{Hasil}

Tabel 1. Frekuensi Penggunaan Metode Kontrasepsi Jangka Panjang pada wanita usia subur di Puskesmas Paal V kota jambi

\begin{tabular}{ccc}
\hline Penggunaan MKJP & F & $\%$ \\
\hline Menggunakan metode selain MKJP & 43 & 45.3 \\
\hline Menggunakan MKJP & 52 & 54.7 \\
\hline
\end{tabular}


Vol. 1, No. 1, Januari 2019

\begin{tabular}{ccc}
\hline Total & 95 & 100.0 \\
\hline
\end{tabular}

Sumber: Data Primer, 2018

Hasil penelitian menunjukkan dari 95 responden, yang tidak menggunakan metode MKJP sebanyak 43 orang, sedangkan responden yang menggunakan MKJPsebanyak 52 orang.

Tabel 2. Distribusi Frekuensi Tingkat Pengetahuan penggunaan metode kontrasepsi jangka panjang pada wanita usia subur di Puskesmas Paal V Kota Jambi

\begin{tabular}{ccc}
\hline Pengetahuan & $\mathrm{f}$ & $\%$ \\
\hline Kurang Baik & 71 & 74.7 \\
\hline Baik & 24 & 25.3 \\
\hline Total & 95 & 100.0 \\
\hline
\end{tabular}

Sumber: Data Primer, 2018

Hasil penelitian menunjukkan bahwa mayoritas pengetahuan wanita usia subur untuk menggunakan MKJP adalah kurang baik sebanyak 71 responden dan responden dengan pengetahuan baik sebanyak 24 responden.

Tabel 3. Distribusi Frekuensi Tingkat Umur dengan penggunaan metode kontrasepsi jangka panjang pada wanita usia subur di Puskesmas Paal V Kota Jambi

\begin{tabular}{cccccccc}
\hline \multirow{2}{*}{ Umur } & \multicolumn{4}{c}{ Pengguna MKJP } & \multirow{2}{*}{ Total } \\
\cline { 2 - 6 } & \multicolumn{2}{c}{ Tidak } & \multicolumn{2}{c}{ Ya } & & \\
\cline { 2 - 6 } & $\mathrm{f}$ & $\%$ & $\mathrm{f}$ & $\%$ & $\mathrm{~F}$ & $\%$ \\
\hline $25-35$ tahun & 38 & 76.0 & 12 & 24.0 & 50 & 100.0 \\
\hline$<20$ dan $>35$ & 5 & 11.1 & 40 & 88.9 & 45 & 100.0 \\
\hline Total & 43 & 45.3 & 52 & 54.7 & 95 & 100.0 \\
\hline
\end{tabular}

Sumber: Data Primer, 2018

Hasil penelitian menunjukkan bahwa mayoritas umur wanita usia subur yang menggunakan MKJP adalah 25-35 tahun sebesar 12 orang. Dan yangmenggunakan MKJP adalah $<20$ tahun dan $>35$ tahun sebesar 40 orang. Dan yang tidak menggunakan MKJP adalah 25-35 tahun sebesar 38 orang. Dan yang tidak menggunakan MKJP adalah $<20$ tahun dan $>35$ tahun sebesar 5 orang.

Tabel 4. Distribusi Frekuensi Partisipasi suami Responden Terhadap penggunaan metode kontrasepsi jangka panjang pada wanita usia subur di Puskesmas Paal V Kota Jambi

\begin{tabular}{|c|c|c|}
\hline Partisipasi Suami & f & $\%$ \\
\hline Tidak Mendukung & 43 & 45.3 \\
\hline Mendukung & 52 & 54.7 \\
\hline Total & 95 & 100.0 \\
\hline
\end{tabular}

Primer, 2018

Sumber: Data

Hasil penelitian menunjukkan bahwa mayoritas partisipasi suami untuk mendukung menggunakan MKJP adalah tinggi yaitu sebesar 52 responden. Dan selebihnya partisipasi suami untuk tidak mendukung menggunakan MKJP sebanyak 43 responden.

Tabel 5. Hubungan Pengetahuan dengan Penggunaan metode kontrasepsi jangka panjang pada wanita usia subur di Puskesmas Paal V Kota Jambi

\begin{tabular}{|c|c|c|c|c|}
\hline \multirow{2}{*}{ Pengetahuan } & \multicolumn{2}{|c|}{ Pengguna MKJP } & \multirow{2}{*}{ Total } & \multirow{2}{*}{$\mathrm{P}=$ value } \\
\hline & Tidak & $\mathrm{Ya}$ & & \\
\hline
\end{tabular}


Vol. 1 , No. 1 , Januari 2019

\begin{tabular}{|c|c|c|c|c|c|c|}
\hline & $\mathrm{F}$ & $\%$ & $\mathrm{~F}$ & $\%$ & & \multirow{4}{*}{.000} \\
\hline Kurang baik & 40 & 56.3 & 31 & 43.7 & 71 & \\
\hline Baik & 3 & 12.5 & 21 & 87.5 & 24 & \\
\hline Total & 43 & 45.5 & 52 & 54.7 & 95 & \\
\hline
\end{tabular}

Sumber: Data Primer, 2018

Tabulasi silang hubungan pengetahuan wanita usia subur tentang penggunaan MKJP menunjukkan bahwa responden dengan pengetahuan kurang baik memiliki sebagian besar tidak menggunakan MKJP sebesar (56.3\%) lebih tinggi dibandingkan dengan yang menggunakan MKJP (43.7\%), sedangkan pada responden dengan pengetahuan baik sebagian besar tidak menggunakan MKJP sebesar (12.5\%) sangat rendah dibandingkan dengan yang menggunakan MKJP (87.5\%), Hasil analisis Chi-square diperoleh nilai signifikansi (p-value) 0,000. Hasil uji menunjukkan nilai signifikansi lebih kecil dari 0,05 $(0,000<0,05)$ maka disimpulkan bahwa $\mathrm{H} 0$ ditolak, artinya terdapat hubungan yang signifikan pengetahuan terhadap penggunaan metode kontrasepsi jangka panjang (MKJP) pada wanita usia subur di Puskesmas Paal V Kota Jambi Tahun 2018.

Tabel 6. Hubungan Umur dengan Penggunaan penggunaan metode kontrasepsi jangka panjang pada wanita usia subur di Puskesmas Paal V Kota Jambi

\begin{tabular}{|c|c|c|c|c|c|c|}
\hline \multirow{3}{*}{ Umur } & \multicolumn{4}{|c|}{ Penggunaan MKJP } & \multirow{3}{*}{ Total } & \multirow{3}{*}{$\mathrm{P}=$ value } \\
\hline & \multicolumn{2}{|c|}{ Tidak } & \multicolumn{2}{|c|}{ Ya } & & \\
\hline & $\mathrm{f}$ & $\%$ & $\mathrm{f}$ & $\%$ & & \\
\hline 20-35 tahun & 38 & 76 & 12 & 24 & 50 & \\
\hline$<20$ tahun dan $>35$ tahun & 5 & 11.1 & 40 & 88.9 & 45 & .000 \\
\hline Total & 43 & 45.3 & 52 & 54.7 & 95 & \\
\hline
\end{tabular}

Sumber: Data Primer, 2018

Tabulasi silang hubungan umur wanita usia subur tentang penggunaan MKJP menunjukkan bahwa responden dengan umur kurang 20-35 tahun tidak menggunakan MKJP sebesar (76\%) lebih tinggi dibandingkan dengan yang menggunakan MKJP (24\%) sedangkan pada responden dengan umur besar dari <20 tahun dan > 35 tahun sebagian besar tidak menggunakan MKJP sebesar (11.1\%) sangat rendah dibandingkan dengan yang menggunakan MKJP (88.9\%) Hasil analisis Chi-square diperoleh nilai signifikansi (p-value) 0,000. Hasil uji menunjukkan nilai signifikansi lebih kecil dari 0,05 $(0,000<0,05)$ maka disimpulkan bahwa H0 ditolak, artinya terdapat hubungan yang signifikan umur terhadap penggunaan metode kontrasepsi jangka panjang (MKJP) pada wanita usia subur di Puskesmas Paal V Kota Jambi Tahun 2018.

Tabel 7. Hubungan Partisipasi Suami dengan penggunaan metode kontrasepsi jangka panjang pada wanita usia subur di Puskesmas Paal V Kota Jambi tahun 2018

\begin{tabular}{c|c|c|c|c|c|c}
\hline \multirow{2}{*}{ Partisipasi suami } & \multicolumn{4}{|c|}{ Pengguna MKJP } & \multirow{3}{*}{ Total } & \multirow{2}{*}{ P=value } \\
\cline { 2 - 6 } & \multicolumn{2}{|c|}{ Tidak } & \multicolumn{2}{c}{ Ya } & & \\
\cline { 2 - 5 } & $\mathrm{F}$ & $\%$ & $\mathrm{f}$ & $\%$ & & \multirow{2}{*}{.000} \\
\hline Tidak mendukung & 41 & 95.3 & 2 & 4.7 & 43 & \\
\hline Mendukung & 2 & 3.8 & 50 & 96.2 & 52 & \\
\hline Total & 43 & 45.3 & 52 & 54.7 & 95 & \\
\hline
\end{tabular}

Sumber: Data Primer, 2018

Tabulasi silang hubungan partisipasi suami tentang penggunaan MKJP menunjukkan bahwa responden yang tidak mendukung dengan menggunakan selain MKJP sebesar (95.3\%) sedangkan pada responden yang mendukung dan menggunakan MKJP (96.2\%). Hasil analisis Chi-square diperoleh nilai signifikansi (p-value) 0,000. Hasil uji menunjukkan nilai signifikansi lebih kecil dari 0,05 
Vol. 1, No. 1, Januari 2019

$(0,000<0,05)$ maka disimpulkan bahwa H0 ditolak, artinya terdapat hubungan yang signifikan partisipasi suami terhadap penggunaan metode kontrasepsi jangka panjang (MKJP) pada wanita usia subur di Puskesmas Paal V Kota Jambi Tahun 2018.

\subsection{Pembahasan}

3.2.1 Gambaran Penggunaan Metode Kontrasepsi Jangka Panjang Pada Wanita Usia Subur di Puskesmas Paal V Kota Jambi Tahun 2018.

Berdasarkan hasil penelitian menunjukkan dari 95 responden, yang tidak menggunakan metode MKJP sebanyak 43 orang dengan persentasi $45.3 \%$ sedangkan responden yang menggunakan MKJP sebanyak 52 orang dengan persentasi $54.7 \%$. Metode kontrasepsi jangka panjang (MKJP) merupakan metode kontrasepsi yang sangat efektif untuk menurunkan angka kelahiran. Metode kontrasepsi jangka panjang adalah kontrasepsi yang dapat dipakai dalam jangka waktu lama, lebih dari 2 tahun, efektif dan efisien untuk tujuan menjarangkan kelahiran lebih dari 3 tahun atau mengakhiri kehamilan pada pasangan yang sudah tidak ingin tambah anak lagi. Jenis metode yang termasuk kedalam MKJP adalah kontrasepsi mantap pria dan wanita (tubektomi dan vasektomi), implant dan IUD.

Penelitian oleh Hariyani tentang rendahnya penggunaan MKJP menunjukan hasil bahwa umur, jumlah anak dan pengetahuan merupakan faktor yang mempengaruhi rendahnya keikutsertaan penggunaan MKJP di Polindes Tebalo Kecamatan Manyar Gresik ${ }^{4}$. Hasil penelitian pengaruh umur didapatkan responden yang lebih muda mempunyai peluang lebih kecil menggunakan MKJP dibandingkan dengan responden yang tua. Responden pengguna non MKJP sebagian besar memiliki anak banyak, sedangkan pengguna MKJP sebagian besar memiliki anak sedikit. Pengetahuan responden pengguna non MKJP sebagian besar berpengetahuan kurang dibandingkan tingkat pengetahuan responden pengguna MKJP. Tingkat pengetahuan sangat mempengaruhi seseorang dalam memilih jenis kontrasepsi yang akan digunakan.

3.2.2 Gambaran pengetahuan Penggunaan Metode Kontrasepsi Jangka Panjang Pada Wanita Usia Subur di Puskesmas Paal V Kota Jambi Tahun 2018.

Berdasarkan hasil penelitian menunjukkan bahwa mayoritas pengetahuan wanita usia subur untuk menggunakan MKJP adalah kurang baik sebanyak 71 responden $(74,7 \%)$ dan responden dengan pengetahuan baik sebanyak 24 responden $(25.3 \%)$. Pengetahuan akseptor KB sangat erat kaitannya terhadap pemilihan alat kontrasepsi, karena dengan adanya pengetahuan yang baik terhadap metode kontrasepsi tertentu akan merubah cara pandang akseptor dalam menentukan kontrasepsi yang paling sesuai dan efektif digunakan, sehingga membuat pengguna KB lebih nyaman terhadap kontrasepsi tersebut dan dengan pengetahuan yang baik akan alat kontrasepsi dapat menghindari kesalahan dalam pemilihan alat kontrasepsi yang paling sesuai bagi pengguna itu sendiri. Karena semakin baik pengetahuan responden, mak tingkat kesadaran responden untuk menggunakan MKJP semakin tinggi.

Penelitian oleh Tsani tentang analisis fakor yang berhubungan dengan pemilihan kontrasepsi menunjukan hasil bahwa Berdasarkan uji risk estimate didapatkan nilai Prevalence Ratio (PR) sebesar 1,912. Artinya, akseptor yang mempunyai pengetahuan kurang dan cukup memiliki peluang untuk memilih metode kontrasepsi non-MKJP sebesar 1,912 atau 2 kali lebih besar dibandingkan dengan akseptor yang memiliki pengetahuan baik.

3.2.3 Gambaran Umur Terhadap Penggunaan Metode Kontrasepsi Jangka Panjang Pada Wanita Usia Subur di Puskesmas Paal V Kota Jambi Tahun 2018.

Berdasarkan hasil penelitian menunjukkan bahwa mayoritas umur wanita usia subur yang menggunakan MKJP adalah 25-35 tahun sebesar 12 orang (24\%). Dan yang menggunakan MKJP adalah $<20$ tahun dan $>35$ tahun sebesar 40 orang (88.9\%). Dan yang tidak menggunakan MKJP adalah 25-35 tahun sebesar 38 orang $(76 \%)$. Dan yang tidak menggunakan MKJP adalah <20tahun dan > 35 tahun sebesar 5 orang $(11.1 \%)$.

Umur merupakan salah satu faktor yang mempengaruhi perilaku seseorang dalam pemakaian alat kontrasepsi, mereka yang berumur tua mempunyai peluang lebih kecil untuk menggunakan alat kontrasepsi dibandingkan dengan yang berumur muda. Seorang perempuan menjadi subur dan dapat melahirkan segera setelah ia mendapatkan haidnya yang pertama (menarke) dan kesuburan seorang perempuanakan terus 
Vol. 1 , No. 1 , Januari 2019

berlangsung sampai mati haid (menopouse). Kehamilan dan kelahiran yang terbaik artinya resikonya paling rendah untuk ibu dan anak adalah antara 20-35 tahun sedangkan persalinan pertama dan kedua paling rendah risikonya bila jarak antara kedua kelahiran adalah 2-4 tahun.

Berdasarkan penelitian Wulandari tentang Faktor-Faktor Yang Mempengaruhi Penggunaan MKJP menunjukan bahwa Analisa kategori usia dengan keikutsertaaan MKJP dengan nilai alpha 5\% menunjukan hasil yaitu nilai $p=0,00 \quad(<0,05)$. Hasil tersebut menunjukan ada hubungan antara usia dengan keikutsertaaan MKJP. Analisis keeratan hubungan antara usia dengan keikutsertaaan MKJP didapatkan nilai $\mathrm{OR}=0,261$, artinya responden dengan usia $>35$ tahun cenderung 10 kali memilih MKJP dibandingkan dengan responden dengan usia 20-35 tahun ${ }^{10}$. Berdasarkan hasil penelitian Wijayanti, dkk di wilayah kerja Puskesmas Kecamatan Sawah Besar diketahui bahwa mayoritas akseptor KB didomiinasi oleh usia 35 - 39 tahun $(24,38 \%)$ usia 30-34 tahun $(21,91 \%)$ dan usia 25-29 tahun $(20,49 \%)^{11}$. Bahwa pada usia $<25$ tahun (15-24 tahun) dan usia > 40 tahun (40-49 tahun) terdapat pula akseptor kb yang menggunakan KB MKJP namun kecil presentasinya yaitu $13.01 \%$ dan $20,14 \%$.

3.2.4 Gambaran Partisipasi Suami Terhadap Penggunaan Metode Kontrasepsi Jangka Panjang Pada Wanita Usia Subur di Puskesmas Paal V Kota Jambi Tahun 2018.

Berdasarkan hasil penelitian menunjukkan bahwa mayoritas partisipasi suami untuk mendukung menggunakan MKJP adalah tinggi yaitu sebesar 52 orang (54.7\%). Dan selebihnya partisipasi suami untuk tidak mendukung menggunakan MKJP sebanyak 43 orang (45.3\%). Secara umum, kaum pria di Indonesia masih sangat rendah partisipasinya dalam pemakaian kontrasepsi dibandingkan dengan negara lainnya. Seperti antara lain : Korea $27 \%$, Sri Lanka $26 \%$, Filipina 24\%, Tiongkok (China) 11\%, Thailand 9\%, Bangladesh 5\% dan di Indonesia hanya 4\%. Agar upaya pengembangan kesehatan reproduksi dan hak-hak reproduksi dapat berjalan baik, kaum pria juga dbutuhkan untuk mengakses informasi dan pelayanan termasuk KB, PMS dan HIV/AIDS.

Partisipasi pria dalam program kb dapat bersifat langsung dan tidak langsung. Partisipasi pria secara langsung dalam program $\mathrm{kb}$ adalah menggunakan salah satu cara atau metode pencegahan kehamilan seperti : vasektomi, kondom, senggama terputus, pantang berkala dan kontrasepsi lainnya yang sedang dikembangkan. Sedangkan partisipasi pria secara tidak langsung dalam program KB yaitu menganjurkan, mendukung atau memberikan kebebasan kepada pasangan untuk menggunakan kontrasepsi. Rendahnya pengetahuan suami terhadap keluarga berencana dan kesehatan reproduksi utamanya kesehatan ibu pada masa sebelum kehamilan, pada saat hamil, bersalin dan saat nifas, akan berakibat rendahnya kesehatan reproduksi ibu. Rendahnya kesehatan ibu dapat berakibat meningkatnya angka kematian ibu bersalin, nifas , kematian bayi, sehingga terkesan adanya diskriminasi gender pada pelayanan KB dan kesehatan reproduksi.

Penelitian oleh Siswanto tentang faktor pemilihan MKJP memiliki hasil dari 48 PUS menyatakan dukungan suami yang tidak mendukung memilih non MKJP sebanyak 28 PUS dan 20 PUS memilih MKJP. Dari hasil analisis diperoleh pula nilain $\mathrm{OR}=0,163$ artinya PUS yang mendapatkan dukungan oleh suaminya mempunyai peluang 0,163 kali untuk memilih jenis kontrasepsi metode kontrasepsi jangka panjang dibandingkan non MKJP.

3.2.5 Hubungan pengetahuan Penggunaan Metode Kontrasepsi Jangka Panjang Pada Wanita Usia Subur di Puskesmas Paal V Kota Jambi Tahun 2018

Tabulasi silang hubungan pengetahuan wanita usia subur tentang penggunaan MKJP menunjukkan bahwa responden dengan pengetahuan kurang baik memiliki sebagian besar tidak menggunakan MKJP sebesar (56.3\%) lebih tinggi dibandingkan dengan yang menggunakan MKJP (43.7\%), sedangkan pada responden dengan pengetahuan baik sebagian besar tidak menggunakan MKJP sebesar (12.5\%) sangat rendah dibandingkan dengan yang menggunakan MKJP (87.5\%), Hasil analisis Chi-square diperoleh nilai signifikansi (p-value) 0,000. Hasil uji menunjukkan nilai signifikansi lebih kecil dari 0,05 $(0,000<0,05)$ maka disimpulkan bahwa H0 ditolak, artinya terdapat hubungan yang signifikan pengetahuan terhadap penggunaan metode kontrasepsi jangka panjang (MKJP) pada wanita usia subur di Puskesmas Paal V Kota Jambi Tahun 2018.

Hasil penelitian menunjukkan bahwa hubungan pengetahuan terhadap penggunaan metode kontrasepsi jangka panjang pada wanita usia subur di Puskesmas Paal V Kota Jambi adalah sangat kuat. 
Vol. 1, No. 1, Januari 2019

Hal tersebut terlihat berdasarkan hasil distribusi penggunaan metode kontrasepsi jangka panjang ditinjau dari pengetahuan $(54,7 \%)$ yang pengetahuan tinggi dan menggunakan metode kontrasepsi jangka panjang.

Berdasarkan kuatnya hubungan pengetahuan dengan penggunaan metode kontrasepsi jangka panjang tersebut, memungkinkan peneliti untuk menyarankan agar kedepannya penkes kesehatan terutama tentang keluarga berencana harus semakin ditingkatkan agar semakin tingginya persentasi wanita usia subur yang menggunakan metode kontrasepsi jangka panjang. Hasil penelitian tentang adanya hubungan antara pengetahuan dengan penggunaan metode kontrasepsi jangka panjang pada wanita usia subur di Pukesmas Paal V ternyata sesuai dengan hasil penelitian terdahulu.

Penelitian Hariyani tentang rendahnya keikutsertaan pengguna metode kontrasepsi jangka panjang pada pasangan usia subur memiliki hasil pengetahuan responden tentang kontrasepsi dikelompok PUS pengguna non MKJP rata rata lebih rendah bila dibandingkan dengan tingkat responden di kelompok PUS pengguna $\mathrm{MKJP}^{4}$. Hal tersebut kemungkinan dikarenakan kurangnya informasi tentang kontrasepsi jangka panjang dari pada kelompok pengguna MKJP. Kurangnya pengetahuan tentang kontrasepsi jangka panjang pada kelompok PUS pengguna non MKJP dapat menunjukan bahwa variabel tersebut merupakan faktor yang mempengaruhi rendahnya keikutsertaan pengguna MKJP pada PUS.

3.2.6 Hubungan Umur Terhadap Penggunaan Metode Kontrasepsi Jangka Panjang Pada Wanita Usia

Subur di Puskesmas Paal V Kota Jambi Tahun 2018.

Tabulasi silang hubungan umur wanita usia subur tentang penggunaan MKJP menunjukkan bahwa responden dengan umur kurang 20-35 tahun tidak menggunakan MKJP sebesar (76\%) lebih tinggi dibandingkan dengan yang menggunakan MKJP (24\%) sedangkan pada responden dengan umur besar dari $<20$ tahun dan > 35 tahun sebagian besar tidak menggunakan MKJP sebesar (11.1\%) sangat rendah dibandingkan dengan yang menggunakan MKJP (88.9\%) Hasil analisis Chi-square diperoleh nilai signifikansi (p-value) 0,000. Hasil uji menunjukkan nilai signifikansi lebih kecil dari $0,05(0,000<0,05)$ maka disimpulkan bahwa H0 ditolak, artinya terdapat hubungan yang signifikan umur terhadap penggunaan metode kontrasepsi jangka panjang (MKJP) pada wanita usia subur di Puskesmas Paal V Kota Jambi Tahun 2018.

Umur merupakan salah satu faktor yang mempengaruhi perilaku seseorang dalam pemakaian alat kontrasepsi, mereka yang berumur tua mempunyai peluang lebih kecil untuk menggunakan alat kontrasepsi dibandingkan dengan yang berumur muda. Berdasarkan hasil penelitian Wijayanti,dkk di wilayah kerja puskesmas kecamatan sawah besar diketahui bahwa mayoritas akseptor KB didomiinasi oleh usia 35 - 39 tahun $(24,38 \%)$ usia 30-34 tahun $(21,91 \%)$ dan usia 25-29 tahun $(20,49 \%)$. Bahwa pada usia $<25$ tahun (15-24 tahun) dan usiia > 40 tahun (40-49 tahun) terdapat pula akseptor kb yang menggunakan KB MKJP namun kecil presentasinya yaitu $13.01 \%$ dan $20,14 \%{ }^{11}$.

Hal ini sejalan dengan penelitian Hariyani tentang rendahnya keikutsertaan penggunaan metode kontrasepsi jangka panjang pada pasangan usia subur dengan hasil variabel umur dengan nilai $\mathrm{p}=0,007$ yang artinya responden berumur < 30 tahun memiliki resiko 6,267 kali tidak menggunakan metode kontrasepsi jangka panjang dibandingkan dengan responden yang berumur $\geq 30$ tahun $^{4}$.

Hal ini sejalan dengan penelitian Wulandari tentang faktor-faktor yang mempengaruhi penggunaan metode kontrasepsi jangkapanjang (mkjp) pada pasanganusia subur di kabupaten sambas, bahwaanalisa kategori usia dengan keikutsertaaan MKJP dengan nilai alpha 5\% menunjukan hasil yaitu nilai $p=0,00$ $(<0,05)^{10}$. Hasil tersebut menunjukan ada hubungan antara usia dengan keikutsertaaan MKJP. Analisis keeratan hubungan antara usia dengan keikutsertaaan MKJP didapatkan nilai $\mathrm{OR}=0,261$, artinya responden dengan usia >35 tahun cenderung 10 kali memilih MKJP dibandingkan dengan responden dengan usia 2035 tahun.

3.2.7 Hubungan Partisipasi Suami Terhadap Penggunaan Metode Kontrasepsi Jangka Panjang Pada Wanita Usia Subur di Puskesmas Paal V Kota Jambi Tahun 2018.

Tabulasi silang hubungan partisipasi suami tentang penggunaan MKJP menunjukkan bahwa responden yang tidak mendukung dengan menggunakan selain MKJP sebesar (95.3\%) lebih tinggi dibandingkan yang tidak mendukung dengan menggunakan MKJP (4.7\%) sedangkan pada responden yang mendukung dengan menggunakan selain MKJP sebesar (3.8\%) sangat rendah dibandingkan yang mendukung dengan menggunakan MKJP (96.2\%). Hasil analisis Chi-square diperoleh nilai signifikansi (p- 
Vol. 1, No. 1, Januari 2019

value) 0,000 . Hasil uji menunjukkan nilai signifikansi lebih kecil dari $0,05(0,000<0,05)$ maka disimpulkan bahwa H0 ditolak, artinya terdapat hubungan yang signifikan partisipasi suami terhadap penggunaan metode kontrasepsi jangka panjang (MKJP) pada wanita usia subur di Puskesmas Paal V Kota Jambi Tahun 2018.

Partisipasi pria dalam program $\mathrm{kb}$ dapat bersifat langsung dan tidak langsung. Partisipasi pria secara langsung dalam program $\mathrm{kb}$ adalah menggunakan salah satu cara atau metode pencegahan kehamilan seperti : vasektomi, kondom, senggama terputus, pantang berkala dan kontrasepsi lainnya yang sedang dikembangkan. Rendahnya pengetahuan suami terhadap keluarga berencana dan kesehatan reproduksi utamanya kesehatan ibu pada masa sebelum kehamilan, pada saat hamil, bersalin dan saat nifas, akan berakibat rendahnya kesehatan reproduksi ibu. Rendahnya kesehatan ibu dapat berakibat meningkatnya angka kematian ibu bersalin, nifas, kematian bayi, sehingga terkesan adanya diskriminasi gender pada pelayanan KB dan kesehatan reproduksi

Berdasarkan penelitian Tsany (2015) tentang analisis faktor yang berhubungan dengan pemilihan metode kontrasepsi jangka panjang pada akseptor kb wanita di Kecamatan Banyubiru dengan hasil menunjukkan bahwa dari 46 responden yang tidak mendapat dukungan dari suami terdapat 8 responden memilih menggunakan MKJP (7,69\%) dan 38 responden memilih menggunakan non-MKJP $(36,54 \%)^{12}$. Dari 58 responden yang mendapat dukungan dari suami terdapat 27 responden memilih menggunakan MKJP $(25,96 \%)$ dan 31 responden memilih menggunakan non-MKJP $(29,31 \%)$.

Analisis bivariat menunjukkan bahwa ada hubungan antara dukungan suami dengan pemilihan MKJP (sig=0,002). Berdasarkan uji risk estimate didapatkan nilai Prevalence Ratio (PR) sebesar 1,546. Artinya, akseptor yang tidak mendapat dukungan dari suami memiliki peluang untuk memilih metode kontrasepsi non-MKJP sebesar 1,546 kali lebih besar dibandingkan dengan akseptor yang mendapat dukungan dari suami.

Penggunaan kontrasepsi merupakan tanggung jawab bersama pria dan wanita sebagai pasangan, sehingga metode kontrasepsi yang dipilih mencerminkan kebutuhan serta keinginan suami dan istri. Suami dan istri harus saling mendukung dalam penggunaan metode kontrasepsi karena keluarga berencana dan kesehatan reproduksi bukan hanya urusan pria atau wanita saja.

Dukungan dari suami dalam penggunaan kontrasepsi sangat diperlukan karena tanpa adanya dukungan dari suami rasa nyaman untuk menggunakan kontrasepsi tidak akan didapatkan, metode kontrasepsi tidak dapat dipaksakan pasangan suami isteri harus bersama memilih metode kontrasepsi yang terbaik, saling kerjasama dalam pemakaian, membiayai pengeluaran kontrasepsi, dan memperhatikan tanda dan bahaya.

\section{KESIMPULAN}

Berdasarkan hasil pembahasan dan penelitian tentang hubungan pengetahuan, umur dan partisipasi suami pada wanita usia subur dengan penggunaan metode kontrasepsi jangka panjang (MKJP) di Puskesmas Paal V Kota Jambi Tahun 2018 maka dapat disimpulkan mayoritas akseptor KB di Puskesmas Paal V menggunakan metode kontrasepsi jangka panjang sebanyak 52 orang dengan presentasi 54,7\%, mayoritas akseptor $\mathrm{KB}$ memiliki pengetahuan kurang baik sebanyak 71 responden dengan presentasi74,7\%, mayoritas akseptor KB yang menggunakan metode kontrasepsi jangka panjang sebesar 40 orang dengan presentasi $88.9 \%$. dan yang tidak menggunakan metode kontrasepsi jangka panjang sebesar 38 orangdengan presentasi $76 \%$, mayoritas akseptor KB yang didukung oleh suaminya sebesar 52 orang dengan presentasi 54,7\%, variabel pengetahuan memiliki hubungan yang signifikan yang menghasilkan $p=v a l u e$ sebesar 0,000 , variabel umur memiliki hubungan signifikan yang menghasilkan $p=$ value sebesar 0,000 , variabel partisispasi suami memiliki hubungan signifikan yang menghasilkan $p=$ value sebesar 0,000 .

\section{DAFTAR PUSTAKA}

[1] Koes, Irianto. Kesehatan Reproduksi. Bandung; Alfabeta. 2015.

[2] BKKBN. Laporan Kinerja Instansi Pemerintahan Tahun 2015 Badan Kependudukan dan Keluarga Berencana Nasional. Jakarta. 2016.

[3] Sarwono, Prawirohardjo. Ilmu Kandungan. Jakarta: PT Bina Pustaka. 2011. 
Vol. 1, No. 1, Januari 2019

[4] Hariyani, P., dkk. Rendahnya Keikutsertaan Pengguna Metode Kontrasepsi Jangka Panjang Pada Pasangan Usia Subur. 2013.

[5] Rino, S., Farich, A. Faktor Pemilihan Metode Kontrasepsi Jangka Panjang (MKJP) Pada Pasangan Usia Subur (PUS) Di Wilayah Kerja Puskesmas Segala Mider Kota Bandar Lampung. Jurnal Dunia Kesmas. 2015. 4(3): pg. 151-156.

[6] Nislawaty. Hubungan Pengetahuan, Pendidikan Dan Status Ekonomi Dengan Pemakaian Metode Kontrasepsi Jangka Panjang (Mkjp) Di Desa Ganting Damai Wilayah Kerja Puskesmas Salo Tahun 2015. Jurnal Kebidanan STIKes Tuanku Tambusai Riau. 2015. Pg 47-59

[7] BKKBN. Survey Demografi dan Kesehatan Indonesia (SDKI) tahun 2017. Jakarta: Badan Kependudukan dan Keluarga Berencana Nasional Indonesia. 2018.

[8] Kemenkes. Profil Kesehatan Indonesia tahun 2016. Jakarta: Kementrian Kesehatan Indonesia. 2017.

[9] Dinkes. Profil Kesehatan Provinsi Jambi Tahun 2016. Jambi: Dinas Kesehatan Provinsi Jambi. 2017

[10] Wulandari., dkk. Faktor-Faktor Yang Mempengaruhi Penggunaan Metode Kontrasepsi Jangka Panjang (MKJP) Pada Pasangan Usia Subur di Kabupaten Sambas. 2016.

[11] Wijayanti, dkk. 2017. Penggunaan KB metode kontrasepsi jangka panjang (MKJP) diwilayah kerja puskesmas kecamatan sawah besar jakarta pusat; jurnal ilmiah widya. 2017. 4(1) edisi januari- juli 2017.

[12] Mahmudah, L, T, N. Analisis Faktor Yang Berhubungan Dengan Pemilihan Metode Kontrasepsi Jangka Panjang (Mkjp) Pada Akseptor Kb Wanita Di Kecamatan Banyubiru Kabupaten Semarang. Unnes Journal of Public Health. 2015. 4(3). 